\title{
Hérnia diafragmática traumática transpericárdica (tréplica)
}

\section{Sra. Editora:}

Não pretendo polemizar a respeito dos métodos diagnósticos nem sobre as condutas de tratamentos cirúrgicos da hérnia diafragmática traumática transpericárdica (HDTP), uma vez que esses aspectos já foram bastante discutidos e divulgados. Contudo, no que tange ao conceito e à incidência dessa hérnia, as respostas do Dr. Roberto Ruben Pando-Serrano à minha carta ao editor ${ }^{(1)}$ deixam muito a desejar e esses dois aspectos merecem ser detalhadamente analisados.

O colega conceitua claramente que a HDTP para ser aceita como transpericárdica o seu conteúdo deve seguir, inicialmente, o mesmo trajeto da intrapericárdica "e, deste, por lesão da parede lateral ou mediastinal, para a cavidade pleural, sem a presença de lesão do hemidiafragma"(1). Desconsidera, assim, os casos de pacientes com conteúdos herniários somente dentro dos respectivos sacos pericárdicos. Para essas hérnias, nos traumas contusos, mantenho o conceito de que sempre acontecem aberturas conjuntas de parte do centro tendinoso diafragmático e de parte do pericárdio justaposto. Essas aberturas podem se estender em qualquer sentido $e$, também, podem ocorrer outras roturas isoladas de ambas as estruturas. Uma vez que o conteúdo herniário passe através do diafragma e do folheto pericárdico, logicamente ele forma uma hérnia diafragmática transpericárdica, independentemente de permanecer na loja pericárdica, alcançar a cavidade pleural ou atingir o mediastino. Além disso, o colega, na introdução e na discussão do seu artigo (2), antes de restringir tais hérnias a seu específico conceito ${ }^{(1)}$ cita, paradoxalmente, como exemplos justificativos do seu caso, diversos trabalhos ${ }^{(3-9)}$, alguns deles também apontados por mim $^{(10)}$, nos quais as hérnias se limitam apenas às cavidades pericárdicas e, dessa maneira, contradiz o seu próprio enunciado.

O mesmo, embora durante o ato cirúrgico do seu paciente não tenha localizado ou identificado conteúdos herniários para dentro do tórax, exceto uma pequena parte do lobo esquerdo do fígado, afirma, por duas vezes $^{(1,2)}$, que houve apenas um outro relato idêntico ao seu nos "últimos 30 anos"(11). Observa-se, assim, outro parcial engano, pois no exemplo citado(11) não houve a redução espontânea do conteúdo herniário, mas sim a passagem para dentro da cavidade pleural de parte do coração, de parte do estômago, de parte do intestino grosso e de parte do epíploo, permanecendo dentro do saco pericárdico porções dessas mesmas estruturas.

A incidência, por mim apontada(10), de 25 casos com conteúdos restritos aos sacos pericárdicos e de 11 casos cujas hérnias alcançavam, da mesma forma, as cavidades pleurais, sendo esses últimos iguais ao seu exemplo mor ${ }^{(11)}$, deve ou não ser levada em conta?

Se considerássemos, ainda, as hérnias diafragmáticas transpericárdicas advindas de traumatismos penetrantes, como alguns casos a que me referi(10), a incidência total não seria bastante distinta?

\author{
ANTONIO SEBASTIÃO PORTO \\ Doutor em Medicina pela Faculdade de Medicina \\ da Universidade de São Paulo; \\ Professor Adjunto IV, aposentado pela \\ Universidade Federal de Mato Grosso do Sul
}

\section{REFERÊNCIAS}

1. Porto AS, Pando-Serrano RR. Hérnia diafragmática traumática transpericárdica (carta ao editor \& resposta). J Pneumol 2001;27:XIX-XX.

2. Pando-Serrano, RR, Leal AJF, Gomes MRA, Crepaldi Filho R. Hérnia diafragmática transpericárdica: relato de caso. J Pneumol 2000;26: 317-320.

3. Meng RL, Straus A, Milloy F, Kittle CF, Langston H. Intrapericardial diaphragmatic hernia in adults. Ann Surg 1979;189:359-366.

4. Adamthwaite DN, Snyders DC, Mirwis SJ. Traumatic pericardiophrenic hernia: a report of 3 cases. Br J Surg 1983;70:117-119.

5. Van Loenhout RMM, Schiphorst TJMJ, Wittens CHA, Pinckaers JA. Traumatic intrapericardial diaphragmatic hernia. J Trauma 1986;26: 271-275.

6. Beless DJ, Organ BC. Delayed presentation of intrapericardial diaphragmatic hernia, an unusual cause of colon obstruction. Ann Emerg Med 1991;20:415-417.

7. Girzadas DV Jr, Fligner DJ. Delayed traumatic intrapericardial diaphragmatic hernia associated with cardiac tamponade. Ann Emerg Med 1991; 20:1246-1247.

8. Aldhoheyan A, Jain SK, Hamdy M, Alsebayel MJ. Traumatic intrapericardial diaphragmatic hernia. Injury 1992;23:331-332.

9. Colliver C, Oller DW, Rose G, Brewer D. Traumatic intrapericardial diaphragmatic hernia diagnosed by echocardiography. J Trauma 1997; 42:115-117.

10. Porto AS, Oshiro Y, Pontes JCDV, Medeiros CGS, Nandes AM, Ovando LA. Hérnia intrapericárdica em trauma contuso: relato de caso $e$ revisão da literatura. Rev Bras Cir Cardiovasc 1998;13:60-70.

11. Bank H, Sinkover H, Ophir M, Shulemson M. Traumatic transpericardial hernia. Br Med J 1971;2:629-630.

Nota da Editora - Os autores Pando-Serrano et al. não responderam à tréplica acima. A Editora considera o assunto definitivamente encerrado. 